\title{
A slow-growing glistening tumor on a female patient's face: what is your diagnosis?
}

\section{Nadia Nabli', Rima Gammoudi', Najet Ghariani'1, Badreddine Sriha ${ }^{2}$, Lobna Boussofara ${ }^{1}$, Mohamed Denguezli ${ }^{1}$}

${ }^{1}$ Department of Dermatology, Farhat Hached University hospital, Sousse, Tunisia, ${ }^{2}$ Department of Anatomopathology, Farhat Hached University hospital, Sousse, Tunisia

Corresponding author: Dr. Nadia Nabli, E-mail: nablinadya@gmail.com

\section{CASE REPORT}

A 59-year-old woman presented with a 5-year history of an asymptomatic slow-growing nodule on the upper lip. The physical examination revealed a well-defined, $15 \times 30 \mathrm{~mm}$ diameter, dome-shaped and firm nodule, with an irregular, telangiectatic and glistening surface (Fig. la). Dermoscopic assessment revealed a dense whitish-brown structureless area with central fine linear branched blood vessels, pigmented ovoid nests and white peripheral clods of variable diameter (Fig. 1b). Histopathological examination of an excisional biopsy, performed using an elliptical excision, revealed dermal invasion with malignant tumor cells arranged in lobules. Severe nuclear atypia was seen in the cells (Fig. lc). On higher magnification, the tumor was composed of small keratin-filled cysts and islands of basaloid keratinocytes. Some of the lobules showed duct-like structures extending into the deeper dermis and surrounded by a sclerotic stroma (Fig. ld).

\section{ANSWER}

Microcystic adnexal carcinoma

\section{DISCUSSION}

Microcystic adnexal carcinoma (MAC) is a rare, slowgrowing, malignant cutaneous neoplasm with pilar and eccrine gland differentiation [1,2]. Clinically, MAC manifests as asymptomatic, slowly growing, and firm nodule, plaque, or cyst-like tumor with well-defined borders and a soft telangiectatic surface,

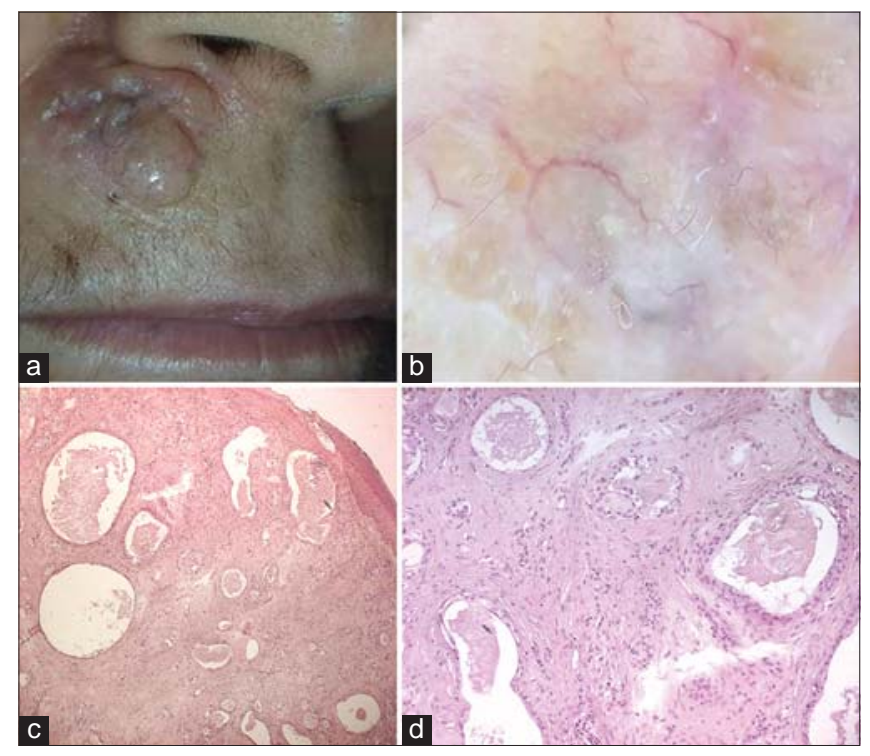

Figure 1: (a) A well-defined, $15 \times 30 \mathrm{~mm}$ diameter, dome-shaped and firm nodule, with an irregular, telangiectatic and glistening surface; (b) Dermoscopic features: a dense whitish-brown structureless area with central fine linear branched blood vessels, pigmented ovoid nests and white peripheral clods of variable diameter; (c) Dermal invasion with malignant tumor cells arranged in lobules (hematoxylin and eosin stain, original magnification $\times 40$ ); (d) Small keratin-filled cysts with duct-like structures extending into the deeper dermis and surrounded by a sclerotic stroma (hematoxylin and eosin stain, original magnification $\times 200$ ).

most commonly located on the head and neck [3]. A search of the literature has discovered few published dermatoscopy images of MAC. The most common dermatoscopic features of the tumor are the dense central whitish-brown structureless area with linear arborizing vessels and the peripheral white-yellowish clods of variable diameter [1,3-5]. The diagnosis is based on histopathological examination of a full thickness biopsy that shows small keratin-filled cysts with nests

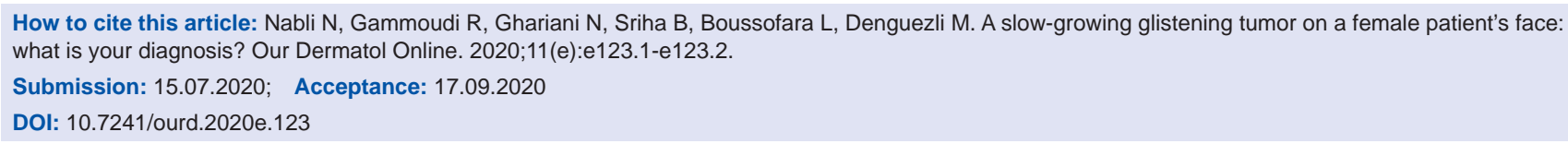


www.odermatol.com

and cords which resemble ductal structures [2]. Radical excision of the tumor is the most recommended therapy with two options including wide local excision with postoperative margin evaluation and Mohs micrographic surgery [2]. Although MAC rarely metastasizes, a long term follow-up is preconized given the high potential for local aggressivity and recurrence $[1,2]$.

\section{REFERENCES}

1. Inskip M, Magee J. Microcystic adnexal carcinoma of the cheek : a case report with dermatoscopy and dermatopathology. Dermatol Pract Concept. 2015;5:7.

2. Aslam, A. Microcystic Adnexal Carcinoma and a Summary of Other Rare Malignant Adnexal Tumours. Curr Treat Options in Oncol.
2017;18:49.

3. Calderón-Castrat X, Román-Curto C, Santos-Briz A, Fernández-López E. Microcystic adnexal carcinoma mimicking basal cell carcinoma. JAAD Case Reports. 2017;3:492-4.

4. Rie S, Shin-ichi A, Azusa O, Hidenori M, Hidehisa S, Masaru T. Dermoscopic findings of microcystic adnexal carcinoma. Eur J Dermatol. 2015;25:516-8.

5. Astorino S, Carelli G, Dattola A, Pasquini P. Microcystic adnexal carcinoma of the skin in atypical site (pubic region): clinical and dermatoscopic features. G Ital Dermatol Venereol. 2020;155:231-2.

Copyright by Nadia Nabli, et al. This is an open-access article distributed under the terms of the Creative Commons Attribution License, which permits unrestricted use, distribution, and reproduction in any medium, provided the original author and source are credited.

Source of Support: Nil, Conflict of Interest: None declared. 